\title{
Trends and sex disparities in school bullying victimization among U.S. youth, 2011-2019
}

\author{
Ruili Li', Qiguo Lian ${ }^{2 *}$ (D), Qiru Su${ }^{3}$, Luhai Li ${ }^{4}$, Meixian $\mathrm{Xie}^{4}$ and Jun $\mathrm{Hu}^{5}$
}

\begin{abstract}
Background: The prevalence of being bullied traditionally among U.S. high school students is expected to reduce to $17.9 \%$, according to Healthy People 2020 Initiatives. We examined trends in traditional victimization and cybervictimization with the latest large-scale time-series data in the United States.

Methods: We analyzed the data from the 2011-2019 national Youth Risk Behavior Survey (YRBS) to access the trends in traditional victimization and cybervictimization among U.S. high school students. We identified the temporal trends using multivariate logistic regression analyses, accounting for survey design features of YRBS. Participants included 72,605 high school students.

Results: The overall prevalence of victimization was 19.74\% for traditional bullying and $15.38 \%$ for cyberbullying, suggesting that cyberbullying is not a low frequent phenomenon. The prevalence of victimization ranged from 20.19 to $19.04 \%$ for traditional victimization and 16.23 to $14.77 \%$ for cybervictimization, and the declined trends for the two kinds of bullying victimization were both statistically non-significant. The degree of overlap between the two kinds of bullying victimization was about $60 \%$. Besides, female students reported more traditional victimization and cybervictimization than male peers within each survey cycle.

Conclusions: No declined trends in traditional victimization and cybervictimization were observed during 20112019. Female students are more likely to experience school bullying. To achieve the Healthy People 2020 goal on bullying, more work is needed to explore the underlying reasons behind these unchanging trends.
\end{abstract}

Keywords: School bullying, Sex disparities, Trends

\section{Background}

School bullying was considered a serious and often overlooked issue for school-aged children [1]. There are four main forms of bullying: physical, verbal, social, and cyber. Globally, more than $10 \%$ of the students reported being bullied in school at least 2-3 times a month according to the 2010 Health Behaviour in School-aged Children (HBSC) study [2]. Bullying victimization is

\footnotetext{
* Correspondence: qglian@fudan.edu.cn

${ }^{2} \mathrm{NHC}$ Key Lab. of Reproduction Regulation (Shanghai Institute of Planned Parenthood Research), Fudan University, Shanghai, China

Full list of author information is available at the end of the article
}

positively associated with mental health problems including depression [3], self-harm [4] and suicidal ideation [5], and externalizing problems [6].

Prof. Dan Olweus of Norway, one of the world's pioneering researchers on bullying, provided strong evidence that compared with traditional verbal bullying(17.3\%), cyberbullying(4.5\%) was still a relatively low-prevalence phenomenon, which didn't increase over time and the degree of overlap with traditional bullying was very high (almost 90\%) using large-scale time-series data sets in United States(2007-2010) [7, 8]. The heterogeneity of empirical prevalence estimates of cyberbullying, according to 
Olweus, can be can be explained by three primary reasons: different reference periods, different cutoff points, and different measurement contexts [9].

Cyberbullying has evolved with the rapid development of technology and social media in the past decade. The trend of cyberbullying victimization during recent years has been poorly studied although traditional bullying has begun to decline among adolescent populations [10]. The 2002-2014 HBSC data in 37 countries suggested linear decreases or no linear trends in traditional victimization in most countries, and a moderate degree of overlap (45.8\%) of traditional victimization and cybervictimization with considerate country variations [11]. However, the previous research failed to examine the trend of cyberbullying victimization because cyberbullying items were introduced to HBSC since 2014.

Given the highly inconsistent findings on trends and degree of overlap in bullying $[9,11,12]$ and the rapid evolution of social media, it's necessary to address this gap using the latest time-series data measuring both traditional victimization and cybervictimization in a national representative sample. Leveraging the data from the 2011-2019 U.S. Youth Risk Behavior Survey (YRBS), our first objective was to estimate the prevalence and the degree of overlap, and examine the trends in traditional victimization and cybervictimization among U.S. high school students. Our second objective was to evaluate the Healthy People 2020 Objective IVP-35, the prevalence of traditional bullying victimization among U.S. high school students was expected to reduce to $17.9 \%$ in YRBS [13].

\section{Methods \\ Data and participants}

The YRBS is an ongoing, biennial, cross-sectional, school-based survey of a representative sample of high school students from across the U.S. that monitors the prevalence of health-related behaviors $[14,15]$. A threestage cluster sample design is used in YRBS to recruit nationally representative samples of students attending public and private schools in grades 9-12 [14, 15]. The anonymous survey uses a computer-scannable questionnaire and takes about $45 \min [14,15]$.

This study drew data $(n=72,605)$ from five cycles of YRBS (2011-2019), considering that YRBS measured both traditional bullying and cyberbullying since 2011 . The overall response rates remained at $>60 \%$ during 2011-2019 [14, 15]. The data used in this secondary analysis are de-identified and publicly available (https:// www.cdc.gov/healthyyouth/data/yrbs), hence no protocol approval from an institutional review board was needed.

\section{Measures}

The YRBS measured traditional victimization and cybervictimization using the same reference period (in the past 12 months). During 2011-2019 YRBS, traditional victimization was assessed by the question "During the past 12 months, have you ever been bullied on school property?" $(\mathrm{No}=0$, Yes =1). During 2011-2015 surveys, cybervictimization was assessed by the question "During the past 12 months, have you ever been electronically bullied? (Include being bullied through e-mail, chat rooms, instant messaging, websites, or texting.)" (No $=0$, Yes $=1$ ). In the 2017-2019 YRBS, the definition of cybervictimization was revised to "Count being bullied through texting, Instagram, Facebook, or other social media". We hence derived a variable to represent three forms of bullying victimization: traditional victimization only, cybervictimization only, and polyvictimization. The degree of overlap between traditional victimization and cybervictimization was measured as the ratio of polyvictimization to cybervictimization, indicating the proportion of participants who experienced cybervictimization also experienced traditional victimization $[8,11]$.

The YRBS included two questions about race and Hispanic heritage since 2007: "Are you Hispanic or Latino?" (Yes $=1$, No $=2)$; What is your race? (Select one or more responses.) (American Indian or Alaska Native $=1$, Asian $=2$, Black or African American $=3$, Native Hawaiian or Other Pacific Islander $=4$, White $=5$ ). Based on the two aforementioned questions, we computed a 4-level race/ ethnicity variable (White $=1$, Black or African American = 2 , Hispanic $/$ Latino $=3$, All Other Races $=4$ ).

We generated grade variable from the question: "In what grade are you?" (9th grade $=1,10$ th grade $=2,11$ th grade $=3,12$ th grade $=4)$, and sex variable from the question: "What is your sex?" (Female $=1$, Male $=2$ ).

\section{Data analysis}

Data were weighted to account for the complex survey design and adjusted for the survey nonresponse. Unweighted sample sizes were presented along with weighted prevalence estimates and corresponding 95\% confidence intervals (CIs). Chi-squared tests of independence were used to examine statistical differences between female and male students across survey years. The trends in traditional victimization and cybervictimization during 2011-2019 by different sex groups were examined using logistic regression models, adjusting for sex, race/ethnicity, and grade [16]. Survey year was used as a continuous variable to assess the linear trend, and quadratic terms of survey year were included to examine the quadratic trend. Only linear time variable was included in the logistic regression models to examine the linear trends, both linear and quadratic time variables were included when examining the quadratic trends [17]. Odds ratios(ORs) and 95\% CIs were reported. Given than the proportion of missing data 
in this study was very small (traditional victimization: $1.80 \%$ on average, cybervictimization: $2.88 \%$ on average), we used pairwise deletion method to deal with missing data.

All analyses were performed using SVY procedures in Stata/SE 15.1 (StataCorp LLC). Statistical significance was considered if a 2-tailed $p$-value was less than 0.05 .

\section{Results}

Of the 72,605 participants from five survey cycles of YRBS, there were $36,497(49.41 \%)$ female students and 361, 08(50.59\%) male students (Table 1$)$. The sample was racially/ethnically diverse and largely composed of White, non-Hispanic students (54.40\%).

During 2011-2019, 19.70\% of the U.S. high school students reported traditional victimization, and $15.44 \%$ reported cybervictimization, female students reported higher prevalences of both traditional victimization and cybervictimization than male students (Table 2). Among high school students, $10.11 \%$ were bullied traditionally only, $5.71 \%$ were cyberbullied only, and $9.73 \%$ were bullied in both ways. Female students reported higher prevalences of both cyber only and poly forms than male students. We further stratified the analyses by survey year and produced consistent results.

Linear and quadratic trend analysis showed that there were no significant changes in the prevalence of U.S. high students who reported traditional victimization or cybervictimization during 2011-2019 (Fig. 1 and Table 3). The overall prevalences were 20.06\% (2011), 19.65\% (2013),

Table 1 Sample Characteristics of high school students: YRBS 2011-2019

\begin{tabular}{llll}
\hline Characteristic & \multicolumn{2}{l}{ No. (Weighted \%) } & \\
\cline { 2 - 4 } & \multicolumn{1}{l}{ Overall } & Male & Female \\
\hline All respondents & $72,605(100)$ & $36,108(100)$ & $36,497(100)$ \\
Grade & & & \\
9th & $18,868(27.26)$ & $9284(27.63)$ & $9584(26.87)$ \\
10th & $18,156(25.68)$ & $9001(25.67)$ & $9155(25.68)$ \\
11th & $18,127(23.98)$ & $9145(23.89)$ & $8982(24.07)$ \\
12th & $17,042(23.09)$ & $8426(22.80)$ & $8616(23.38)$ \\
Race/ethnicity & & & \\
White, non-Hispanic & $31,329(54.40)$ & $15,601(54.31)$ & $15,728(54.48)$ \\
Black, non-Hispanic & $12,236(13.55)$ & $6020(13.67)$ & $6216(13.42)$ \\
Hispanic & $19,781(22.42)$ & $9777(22.38)$ & $10,004(22.46)$ \\
Other, non-Hispanic & $7787(9.64)$ & $3866(9.64)$ & $3921(9.63)$ \\
Survey cycle (year) & & & \\
2011 & $15,364(21.16)$ & $7656(21.56)$ & $7708(20.74)$ \\
2013 & $13,571(18.68)$ & $6950(18.47)$ & $6621(18.89)$ \\
2015 & $15,506(21.34)$ & $7749(21.64)$ & $7757(21.04)$ \\
2017 & $14,638(20.17)$ & $7112(19.65)$ & $7526(20.69)$ \\
2019 & $13,526(18.65)$ & $6641(18.67)$ & $6885(18.64)$ \\
\hline
\end{tabular}

20.19\% (2015), 19.04\% (2017), and 19.52\% (2019) for traditional victimization, and 16.23\% (2011), 14.77\% (2013), $15.55 \%$ (2015), $14.94 \%$ (2017), and $15.71 \%$ (2019) for cybervictimization (Table 2). The sex-stratified analysis resulted in similar findings. It should be noted that although the $p$ value of linear trend analysis in male students $(p=$ 0.031) was less than 0.05 , the $95 \%$ CI did include 1.00 , hence we considered it statistically non-significant.

The degree of overlap between traditional victimization and cybervictimization in our study was moderate. Overall, of students who reported cybervictimization, $63.02 \%$ also reported traditional victimization (Table 2). The overall degree of overlap ranged from $57.42 \%$ (2011) to $66.33 \%$ (2017), this degree ranged from $55.90 \%$ (2011) to $65.69 \%$ (2017) for male students, and from 58.20\% (2011) to $66.85 \%$ (2019) for female students. We also observed a lower degree of overlap among male students in each survey year and the pooled sample.

\section{Discussion}

The main findings of this study are we did not observe a downward trend in both forms of bullying victimization, and more female students reported being bullied compared with male students, both traditionally and electronically. These findings echoed the previous findings $[18,19]$, and highlighted the gap between reality and the Healthy People 2020 goal on reducing bullying and identify female students as the priority group.

Olweus concluded that compared with traditional bullying, the prevalence of cyberbullying was actually quite low using the time series data from two large-scale studies in the U.S. and Norway [7]. The average across time prevalences of being bullied verbally and electronically were 17.6 and $4.5 \%$ in the U.S. sample (total $n=447,000$ ), and 11.0 and $3.4 \%$ in Norwegian data (total $n=45,000$ ) [7]. However, according to YRBS data, there were 19.70 and $15.44 \%$ of high school students who were exposed to traditional bullying and cyberbullying respectively during 2011-2019, indicating that cyberbullying, in the past decade, is not a low frequent phenomenon [20], at least among U.S. adolescents.

In spite of increasing accessibility to smartphones and other internet devices, Olweus found that there was no growth trend in the prevalence of cybervictimization during 2006-2010, neither did the traditional victimization $[7,8]$. For cybervictimization, the prevalence ranged from 15.4 to $18.4 \%$ in the U.S. and from 10.3 to $11.75 \%$ in Norway; for traditional victimization, the results were $15.4-18.4 \%$ in the U.S. and $10.3-11.7 \%$ in Norway [7]. We achieved a similar conclusion from YRBS data. Among U.S. high school students, the prevalences of cybervictimization and traditional victimization were both unchanged significantly from 2011 to 2019. In the past decade, the prevalence ranged from 14.77 to $16.23 \%$ for cybervictimization and from 19.04 to $20.19 \%$ for traditional victimization. 
Table 2 Weighted percentage of school bullying victimization by survey cycle and sex: YRBS 2011-2019

\begin{tabular}{|c|c|c|c|c|c|c|}
\hline \multirow{2}{*}{$\begin{array}{l}\text { Survey } \\
\text { cycle } \\
\text { and sex }\end{array}$} & \multicolumn{3}{|l|}{ School bullying forms } & \multicolumn{2}{|c|}{ School bullying victimization } & \multirow{2}{*}{$\begin{array}{l}\text { Overlap } \\
\text { Both/Cyber } \\
\%\end{array}$} \\
\hline & $\begin{array}{l}\text { Traditional only } \\
\text { Weighted\%(95\%Cl) }\end{array}$ & $\begin{array}{l}\text { Cyber only } \\
\text { Weighted\%(95\%Cl) }\end{array}$ & $\begin{array}{l}\text { Both(poly-victimized) } \\
\text { Weighted\%(95\%Cl) }\end{array}$ & $\begin{array}{l}\text { Traditional } \\
\text { Weighted\%(95\%Cl) }\end{array}$ & $\begin{array}{l}\text { Cyber } \\
\text { Weighted\%(95\%Cl) }\end{array}$ & \\
\hline \multicolumn{7}{|l|}{2011} \\
\hline Overall & 11.39 (10.13-12.78) & $6.81(6.25-7.41)$ & $9.32(8.43-10.30)$ & $20.06(18.61-21.59)$ & $16.23(15.21-17.31)$ & 57.42 \\
\hline Male & $12.84(11.32-14.53)$ & $4.68(4.03-5.44)$ & $6.01(4.89-7.35)$ & $18.24(16.52-20.10)$ & $10.75(9.59-12.04)$ & 55.90 \\
\hline Female & $9.82(8.59-1122)$ & $9.10(8.27-10.01)$ & $12.87(11.59-14.27)$ & 21.99 (20.42-23.64) & $22.11(20.60-23.71)$ & 58.20 \\
\hline \multicolumn{7}{|l|}{2013} \\
\hline Overall & $10.47(9.79-11.19)$ & $5.58(5.08-6.13)$ & $9.20(8.41-10.05)$ & 19.65 (18.46-20.89) & $14.77(13.68-15.92)$ & 62.28 \\
\hline Male ${ }^{* * *}$ & $10.29(9.26-11.41)$ & $3.26(2.70-3.93)$ & $5.29(4.69-5.95)$ & $15.55(14.25-16.96)$ & $8.54(7.70-9.47)$ & 61.94 \\
\hline Female & $10.63(9.89-11.42)$ & $7.91(7.00-8.92)$ & $13.11(11.72-14.64)$ & $23.72(22.14-25.38)$ & $21.01(19.15-23.00)$ & 62.39 \\
\hline \multicolumn{7}{|l|}{2015} \\
\hline Overall & $10.26(9.14-11.51)$ & $5.61(4.98-6.31)$ & $9.96(9.12-10.86)$ & 20.19 (18.69-21.78) & $15.55(14.37-1680)$ & 64.05 \\
\hline Male & $10.00(8.80-11.34)$ & $3.84(3.21-4.59)$ & $5.84(4.84-7.03)$ & $15.81(14.42-17.31)$ & $9.66(8.45-1103)$ & 60.45 \\
\hline Female & $10.50(9.10-12.09)$ & $7.44(6.52-8.48)$ & $14.30(12.87-15.86)$ & $24.79(22.75-26.96)$ & $21.74(19.86-23.75)$ & 65.77 \\
\hline \multicolumn{7}{|l|}{2017} \\
\hline Overall & $9.14(8.44-9.90)$ & $5.04(4.57-5.56)$ & $9.91(8.99-10.91)$ & $19.04(17.71-20.44)$ & $14.94(13.77-16.18)$ & 66.33 \\
\hline Male & $9.09(8.13-10.15)$ & $3.41(2.92-3.97)$ & $6.51(2.85-7.25)$ & $15.58(14.46-16.78)$ & $9.91(9.19-10.68)$ & 65.69 \\
\hline Female & $9.26(8.45-10.14)$ & $6.66(5.78-7.67)$ & 13.09 (11.44-14.95) & $22.34(20.21-24.62)$ & $19.74(17.48-22.21)$ & 66.31 \\
\hline \multicolumn{7}{|l|}{2019} \\
\hline Overall & $9.29(8.33-10.35)$ & $5.50(4.85-6.24)$ & $10.23(9.24-11.32)$ & $19.52(17.89-21.26)$ & $15.71(14.40-17.12)$ & 65.12 \\
\hline Male & 8.57 (7.47-9.80) & $4.14(3.47-4.94)$ & $6.80(5.83-7.91)$ & $15.36(13.77-17.09)$ & $10.92(9.56-12.44)$ & 62.27 \\
\hline Female & $9.98(8.80-11.29)$ & $6.77(5.84-7.84)$ & $13.63(12.23-15.17)$ & $23.60(21.44-25.90)$ & $20.39(18.63-22.27)$ & 66.85 \\
\hline \multicolumn{7}{|l|}{ 2011-2019 } \\
\hline Overall & $10.11(9.66-10.59)$ & $5.71(5.44-5.98)$ & $9.73(9.35-10.12)$ & 19.70 (19.10-20.31) & $15.44(14.96-15.94)$ & 63.02 \\
\hline Male & $10.18(9.62-10.77)$ & $3.87(3.59-4.18)$ & $6.08(5.66-6.54)$ & $16.14(15.49-16.82)$ & $9.96(9.44-10.51)$ & 61.04 \\
\hline Female & $10.03(9.51-10.58)$ & $7.57(7.15-8.01)$ & $13.41(12.8-14.04)$ & $23.29(22.47-24.13)$ & $21.00(20.22-21.79)$ & 63.86 \\
\hline
\end{tabular}

Abbreviation: $\mathrm{Cl}$ confidential interval

${ }^{* * *}$ Differences in bullying among male and female students are all statistically significant $(P<0.001)$

Large studies have indicated that there is a substantial overlap between cybervictimization and traditional victimization [21, 22], and the degree of overlap varies from over 90 [7] to 50\% [23]. Olweus argued that cyberbullying created a few additional bullying victims, given that the degree of overlap was up to $88 \%$ in the U.S. and $93 \%$ in Norway $[7,22]$. However, YRBS data showed that the degree of overlap was only about $60 \%$, and the overall prevalence of being cyberbullied only was 5.74\% during 20112019, which meant that contrary to findings from Olweus, cyberbullying actually added a few new victims at least among U.S. adolescents.

Healthy People 2020 provides science-based national objectives for improving the health of Americans during 2011-2020. Healthy People 2020 objective IVP-35 is to reduce the prevalence of traditional victimization in the previous 12 months before the survey among U.S. high school students from 19.9 to $17.9 \%$ [13]. However, YRBS data showed that during 2011-2019, the prevalence of traditional victimization ranged from 21.99 to $19.04 \%$ and no linear decrease occurred, which suggested that more work is needed to address the issue of school bullying in the next few years. To achieve the Healthy People 2020 bullying goal [24], priority groups should be identified first. Consistent with the results from previous studies in U.S. high school students $[14,18,25,26]$, in our study, female students reported higher prevalences of both cybervictimization and traditional victimization than male peers across the survey cycles, indicating that there are sex disparities in traditional and cyberbullying. The underlying cause for the unchanged trends for both female and male students may be that existing anti-bullying initiatives could reduce verbal and physical bullying effectively, but not relational bullying [19]. Relational bullying victimization ranked as the top bullying form among U.S. adolescents, and female students were more likely to be involved in relational bullying according to the 2010 HBSC U.S. study [27]. 


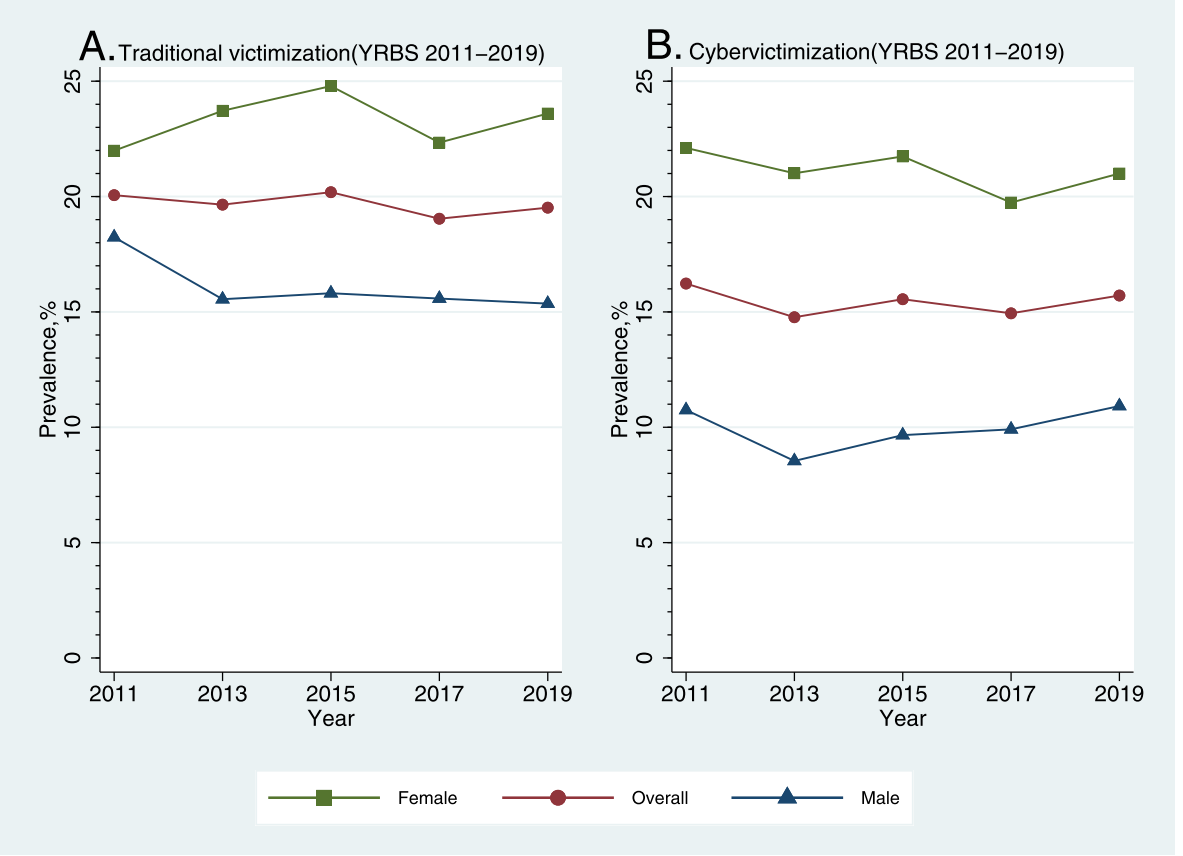

Fig. 1 School bullying victimization trends by sex groups: YRBS 2011-2019

Our findings have significant implications for policy and research practice. Policymakers should acknowledge the sex disparities in bullying victimization and give high priority to evidence-based interventions that focus on female students and relational bullying. Given that the prevalence of cybervictimization has remained high and stable among U.S. adolescents during the last decade, researchers need to follow the evolution of bullying in the digital era, investigate its effects on adolescent health, and evaluate the effectiveness of the interventions.

The findings in this study are subject to at least four limitations. First, YRBS data are self-reported, and the experience of being bullied traditionally or electronically may be affected by retrospective recall and social desirability biases [28]. Second, it should be noted that identical or similar measurement properties, including reference period, cutoff point, and context of bullying, must be used to compare the results from different studies. The recommended cutoff for the classification of being bullied is 2 or 3 times per month or more [22]. YRBS used at least once in the past 12 months for the criterion for classification, which led to higher prevalence estimates compared with Olweus's studies. Third, we measured traditional victimization and cybervictimization by one single item respectively. The use of the single-item measure might possess non-optimal psychometric properties, however, the single-item measure can capture enough information when estimating and comparing the prevalence of bullying victimization [29]. Last, it was not possible to identify the reasons behind the nondeclines in school bullying using YRBS data.

\section{Conclusion}

Given that prevalence estimates of bullying victimization unchanged between 2011 and 2019, more work in

Table 3 Trends for school bullying victimization by sex groups: YRBS 2011-2019

\begin{tabular}{|c|c|c|c|c|c|}
\hline \multirow[t]{2}{*}{ Sex } & \multirow[t]{2}{*}{ Trends } & \multicolumn{2}{|c|}{ Traditional bullying victimization } & \multicolumn{2}{|c|}{ Cyberbullying victimization } \\
\hline & & OR $(95 \% \mathrm{Cl})$ & $P$ value & OR $(95 \% \mathrm{Cl})$ & $P$ value \\
\hline \multirow[t]{2}{*}{ Overall } & Linear & $0.99(0.96-1.02)$ & 0.468 & $0.99(0.96-1.02)$ & 0.471 \\
\hline & Quadratic & $1.00(0.97-1.02)$ & 0.838 & $1.01(0.99-1.04)$ & 0.220 \\
\hline \multirow[t]{2}{*}{ Male } & Linear & $0.96(0.93-1.00)$ & 0.031 & $1.02(0.97-1.06)$ & 0.456 \\
\hline & Quadratic & $1.02(0.99-1.05)$ & 0.234 & $1.04(1.00-1.08)$ & 0.076 \\
\hline \multirow[t]{2}{*}{ Female } & Linear & $1.01(0.98-1.05)$ & 0.455 & $0.98(0.95-1.01)$ & 0.113 \\
\hline & Quadratic & $0.98(0.95-1.01)$ & 0.173 & $1.00(0.98-1.03)$ & 0.793 \\
\hline
\end{tabular}

Abbreviations: OR Odds ratio, $\mathrm{Cl}$ confidential interval 
policies, programs, and practices might be needed in the next few years to reach Healthy People 2020 targets for reducing the bullying disparities among U.S. high school students [24]. And cyberbullying is not a relatively low frequent phenomenon compared with traditional bullying among U.S. high school students, and should not be ignored, especially among female students [30].

\section{Abbreviations}

HBSC: Health Behaviour in School-aged Children; YRBS: Youth Risk Behavior Survey; OR: Odds ratio; Cl: Confidence interval

\section{Acknowledgments}

We would like to appreciate U.S. Centers for Disease Control and Prevention for the efforts on data sharing of Youth Risk Behavior Survey. In addition, we are delighted to dedicate this article to the forthcoming baby of Ruili Li, the first author.

\section{Authors' contributions}

QL designed the study and helped with result interpretation. RL and QS drafted the manuscript. $L L$ and $M X$ analyzed the data. JH contributed to the analytics strategy and manuscript improvement. All authors have read and approved the manuscript.

\section{Funding}

This research did not receive any specific grant from funding agencies in the public, commercial, or not-for-profit sectors.

\section{Availability of data and materials}

Data is available at https://www.cdc.gov/healthyyouth/data/yrbs/index.htm.

\section{Ethics approval and consent to participate}

No ethical approval was required because all data were de-identified and publicly available.

\section{Consent for publication}

Not Applicable.

\section{Competing interests}

The authors declare that they have no competing interests.

\section{Author details}

'Children Health and Development Department, Capital Institute of Paediatrics, Beijing, China. ${ }^{2} \mathrm{NHC}$ Key Lab. of Reproduction Regulation (Shanghai Institute of Planned Parenthood Research), Fudan University, Shanghai, China. ${ }^{3}$ Shenzhen Children's Hospital, Shenzhen, Guangdong, China. ${ }^{4}$ Wanrong Maternal and Child Care Service Centre, Wanrong, Shanxi, China. ${ }^{5}$ Huajing Community Health Service Center, Shanghai, China.

Received: 23 April 2020 Accepted: 12 October 2020

Published online: 21 October 2020

\section{References}

1. Swearer SM, Espelage DL, Napolitano SA. Bullying prevention and intervention: realistic strategies for schools: Guilford press; 2009.

2. Lian Q, Su Q, Li R, Elgar FJ, Liu Z, Zheng D. The association between chronic bullying victimization with weight status and body self-image: a crossnational study in 39 countries. PeerJ. 2018;6:e4330.

3. Chou WJ, Wang PW, Hsiao RC, Hu HF, Yen CF. Role of school bullying involvement in depression, anxiety, Suicidality, and low self-esteem among adolescents with highfunctioning autism Spectrum disorder. Front Psychiatry. 2020;11:9.

4. Fisher HL, Moffitt TE, Houts RM, Belsky DW, Arseneault L, Caspi A. Bullying victimisation and risk of self harm in early adolescence: longitudinal cohort study. BMJ. 2012;344:e2683.

5. Bannink R, Broeren S, van de Looij - Jansen PM, de Waart FG, Raat H: Cyber and traditional bullying victimization as a risk factor for mental health problems and suicidal ideation in adolescents. PLoS One 2014, 9(4):e94026.

6. Pengpid S, Peltzer K. Bullying victimization and externalizing and internalizing symptoms among in-school adolescents from five ASEAN countries. Child Youth Serv Rev. 2019;106:104473.
7. Olweus D. Cyberbullying: an overrated phenomenon? Eur J Dev Psychol. 2012;9(5):520-38.

8. Olweus D. School bullying: development and some important challenges. Annu Rev Clin Psychol. 2013;9:751-80

9. Olweus D, Limber SP. Some problems with cyberbullying research. Curr Opin Psychol. 2018;19:139-43.

10. Sinclair KO, Bauman S, Poteat VP, Koenig B, Russell ST. Cyber and bias-based harassment: associations with academic, substance use, and mental health problems. J Adolesc Health. 2012;50(5):521-3.

11. Cosma A, Walsh SD, Chester KL, Callaghan M, Molcho M, Craig W, Pickett W. Bullying victimization: time trends and the overlap between traditional and cyberbullying across countries in Europe and North America. Int J Public Health. 2020;65(1):75-85.

12. Kubiszewski V, Fontaine R, Potard C, Auzoult L. Does cyberbullying overlap with school bullying when taking modality of involvement into account? Comput Hum Behav. 2015:43:49-57.

13. Healthy People 2020 [http://www.healthypeople.gov/2020/].

14. Kann L, McManus T, Harris WA, Shanklin SL, Flint KH, Queen B, Lowry R, Chyen D, Whittle L, Thornton J, et al. Youth risk behavior surveillance United States, 2017. MMWR Surveill Summ. 2018;67(8):1-114.

15. Underwood JM, Brener N, Thornton J, Harris WA, Bryan LN, Shanklin SL, Deputy N, Roberts AM, Queen B, Chyen D, et al. Overview and methods for the youth risk behavior surveillance system - United States, 2019. MMWR Suppl. 2020;69(1):1-10.

16. Esser MB, Clayton H, Demissie Z, Kanny D, Brewer RD. Current and binge drinking among high school students - United States, 1991-2015. MMWR Morb Mortal Wkly Rep. 2017;66(18):474-8.

17. Lindsey MA, Sheftall AH, Xiao Y, Joe S. Trends of suicidal behaviors among high school students in the United States: 1991-2017. Pediatrics. 2019;144(5):e20191187.

18. Kann L, McManus T, Harris WA, Shanklin SL, Flint KH, Hawkins J, Queen B, Lowry R, Olsen EO, Chyen D, et al. Youth risk behavior surveillance - United States, 2015. MMWR Surveill Summ. 2016;65(6):1-174.

19. Pontes NMH, Ayres CG, Lewandowski C, Pontes MCF. Trends in bullying victimization by gender among U.S. high school students. Res Nurs Health. 2018;41(3):243-51

20. Hinduja S, Patchin JW. Cyberbullying: neither an epidemic nor a rarity. Eur J Dev Psychol. 2012;9(5):539-43.

21. Waasdorp TE, Bradshaw CP. The overlap between cyberbullying and traditional bullying. J Adolesc Health. 2015;56(5):483-8.

22. Olweus D. Comments on cyberbullying article: a rejoinder. Eur J Dev Psychol. 2012;9(5):559-68

23. Ybarra ML, Mitchell KJ. Online aggressor/targets, aggressors, and targets: a comparison of associated youth characteristics. J Child Psychol Psychiatry. 2004;45(7):1308-16.

24. Hatzenbuehler ML, Schwab-Reese L, Ranapurwala SI, Hertz MF, Ramirez MR. Associations between Antibullying policies and bullying in 25 states. JAMA Pediatr. 2015:169(10):e152411.

25. Kann L, Kinchen S, Shanklin SL, Flint KH, Kawkins J, Harris WA, Lowry R, Olsen EO, McManus T, Chyen D, et al. Youth risk behavior surveillance-United States, 2013. MMWR Suppl. 2014;63(4):1-168.

26. Eaton DK, Kann L, Kinchen S, Shanklin S, Flint KH, Hawkins J, Harris WA, Lowry R, McManus T, Chyen D, et al. Youth risk behavior surveillance United States, 2011. MMWR Surveill Summ. 2012;61(4):1-162.

27. Wang J, lannotti RJ, Nansel TR. School bullying among adolescents in the United States: physical, verbal, relational, and cyber. J Adolesc Health. 2009:45(4):368-75.

28. Sawyer AL, Bradshaw CP, O'Brennan LM. Examining ethnic, gender, and developmental differences in the way children report being a victim of "bullying" on self-report measures. J Adolesc Health. 2008;43(2):106-14.

29. Solberg ME, Olweus D. Prevalence estimation of school bullying with the Olweus bully/victim questionnaire. Aggress Behav. 2003;29(3):239-68.

30. Spears BA, Taddeo C, Barnes A. 6 - Online social marketing approaches to inform cyber/bullying prevention and intervention: What have we learnt? In: Campbell M, Bauman S, editors. Reducing Cyberbullying in Schools: Academic Press; 2018. p. 75-94.

\section{Publisher's Note}

Springer Nature remains neutral with regard to jurisdictional claims in published maps and institutional affiliations. 